\title{
Performance Evaluation of Asphalt Binder Modified by Natural Rock Asphalt
}

\author{
Khalid Awadh Mohammed ${ }^{1 *}$, Ali I. Mansi², Yasir R. Hussein ${ }^{1}$ \\ ${ }^{1}$ Department of Chemical Engineering, College of Engineering, University of Anbar, Ramadi 310011, Iraq \\ ${ }^{2}$ Department of Civil Engineering, College of Engineering, University of Anbar, Ramadi 310011, Iraq
}

Corresponding Author Email: khalid_awad10@uoanbar.edu.iq

https://doi.org/10.18280/rcma.310504

Received: 4 September 2021

Accepted: 25 October 2021

\section{Keywords:}

natural rock asphalt, modified asphalt, performance, flash point, improvement

\begin{abstract}
Rock asphalt is one of the widely distributed resources in nature. Therefore, this study employs natural rock asphalt as an additive. The focus of this study is to look at the potential of using natural rock asphalt as an asphalt binder modifier. The study looks at five different percentages of modified asphalt (NRA) concentration from Anbar factory asphalt for oxidized bitumen: $0 \%, 5 \%, 10 \%, 20 \%$, and $30 \%$. The results show that using modified natural rock asphalt increased the mechanical qualities of basic asphalt, such as penetration and softening point, flash point, and viscosity. In addition, the current results show that the asphaltic materials that can be used in paving according to the measuring of conventional tests such as ductility, penetration, and others. Furthermore, the findings indicate that modified asphalt has lower temperature sensitivity.
\end{abstract}

\section{INTRODUCTION}

Asphalt is a dark brown to black cement material that is commonly used worldwide. In the 1830s, asphalt was widely used in France and England for sidewalks, flat roofs, and the lining of tanks. In the United States, more than $85 \%$ of asphalt is used to make asphalt concrete road surfaces. Both natural and petroleum-based asphalt are used commercially. It is the result of the deposition of organisms, microscopic algae, and other organisms in the mud of the ocean or the bottom of a lake. Thus, natural asphalt is generated by these residues in the Earth's heat (more than $50^{\circ} \mathrm{C}$ ). However, most of the asphalt in use today is made from the finely refined residues of selected crude oil distillation. Anbar factory asphalt for oxidized asphalt was used in this study [1].

Asphalt is a thermoplastic, viscoelastic liquid that exhibits elastic behavior below its glass transition temperature and/or under rapid loading, and viscous behavior above the glass transition temperature and/or under slow loading. The rheological characteristics of asphalt binders are considered simple [2]. Natural Rock Asphalt (NRA) is a type of asphalt created by fuel seeping through rock splits. Millions of years of accumulation and modifications result in the formation of microbial sludge. The NRA is rich in asphalt and nitrogen and was created by the depositing of Jurassic marine animal fossils [3].

Natural asphalts, such as aljabhaa natural rock asphalt, are frequently utilized for asphalt binder modification in directive to increase the stiffness and deformation resistance of the asphalt mixture. Natural asphalt comes in a variety of forms and purity levels, including asphalt sediment, lake let tar, and rock asphalt. Aljabhaa natural rock asphalt is arguably the most well-known natural asphalt source [4]. To overcome the primary rutting deficiency of asphalt pavement, a new brand of enhanced asphalt with outstanding thermal stability is required. It must also meet asphalt pavement durability requirements, like lower temperature cracking durability, fatigue resistance, and moisture susceptibility. The outstanding characteristics of rock asphalt (RA) modified asphalt have recently garnered study attention [4-7].

Numerous researches displayed that the characteristics and modification results of rock asphalt depend on the rock asphalt sources and chemical composition. The rock asphalt in Xinjiang, China, was recycled to improve the petroleum bitumen. Dissimilar doses of RA with five different levels of dose were added to the petroleum mixture. The rock asphalt enhances high-temperature performance as well as wear resistance. Overall, the RA is a great way to increase the performance of petroleum bitumen [8]. Iraqi asphalt has been used in $20 \%, 35 \%$ and $50 \%$ of bitumen changes by weight in three studies. The mechanical characteristics of the mixtures made from different natural asphalt (NA) modified bitumen amounts were compared with 4\% SBS modified bitumen. Overall, 35\% NA, the blends showed higher performance, with the effect of repeated loads being strongly resisted [9].

Ma and Zhang [10] studied the potential of using natural rock asphalt as a modified base asphalt. They discovered that adding natural asphalt decreases the penetration and ductility characteristics while boosting the softening point. Modified asphalt's temperature sensitivity is also decreased. This study focused on the results of a sequence of valuations of the characteristics of asphalt binders by improving the temperature resilience and reducing the temperature sensitivity of asphalt. Liu et al. [11] used styrene butadiene rubber to evaluate the low-temperature performance of Buton rock asphalt (BRA) modified asphalt. Elementary mechanical property experiments, excluding penetration and soft point experiments, were used to establish the optimal SBR content. The fatigue test at ${ }^{\circ} \mathrm{C}$ was meant to evaluate the anti-friction capability of the styrene butadiene rubber-Buton rock asphalt- 
modified asphalt mixture in the low temperature range. The results of the tests showed that it had the same road performance as the SBS-modified asphalt mixture. Li et al. [12] studied the potential of using original RA and its reformed asphalt mixture, but not the rutting issue. The results showed that the freeze-thaw splitting strength ratios of modified asphalt mixtures were at least $9.5 \%$ greater than those of base asphalt mixtures. In addition, although modified asphalt and its blends exhibit a minor decrease in low temperature performance, they nonetheless meet the standards for zones with a minimum temperature of $\left(-21.5^{\circ} \mathrm{C}\right)$. Furthermore, because the characteristics of rock asphalt can vary substantially based on the type and amounts of the components, it was discovered that the rock asphalt quality and sources had a considerable impact on the modification results [13].

Though considerable studies have been conducted on rock asphalt, there are still some research gaps at this time. The majority of present research focuses on specific characteristics of the rock asphalt binder or rock asphalt combination, like fatigue or high-temperature resistance. Simultaneously, little research has been conducted on the use of rock asphalt, established on anti-rutting enactment, among to the overall achievement of the rock asphalt combination.

Therefore, the focus of this paper is to modify asphalt by adding natural rock asphalt in various percentages. In this study, the asphalt was modified asphalt by adding natural rock asphalt in various percentages. Accordingly, the study obtained the modified asphaltic materials which can be used in paving according to the measuring of conventional tests such as ductility, penetration, and others. In order to achieve the paper's objectives, the paper's layout includes materials and methods, results and discussion, and conclusion.

\section{MATERIALS AND METHODS}

\subsection{Asphalt}

The (40-50) penetration grade asphalt used in our research was collected from one source, which is the Al-Anbar plant for the production of oxidized asphalt. Table 1 shows the physical characteristics of the employed bitumen.

Table 1. The physical characteristics of the used bitumen

\begin{tabular}{|c|c|c|c|}
\hline Characteristic & $\begin{array}{c}\text { ASTM } \\
\text { Specification }\end{array}$ & $\begin{array}{c}\text { Test } \\
\text { Condition } \\
\text { and Units }\end{array}$ & $\begin{array}{c}\text { Al-Anbar } \\
\text { Asphalt } \\
\text { Before } \\
\text { Addition } \\
\end{array}$ \\
\hline Penetration & ASTM D-5 & $\begin{array}{c}25^{\circ} \mathrm{C}, 100 \mathrm{gm} ., \\
5 \mathrm{sec}, 0.1 \mathrm{~mm}\end{array}$ & 45 \\
\hline Ductility & ASTM D-113 & $25^{\circ} \mathrm{C}, \mathrm{cm}$ & $<150 \mathrm{~cm}$ \\
\hline Softening Point & ASTM D-36 & $\begin{array}{l}\text { Ring \& Ball } \\
\text { Method }\end{array}$ & $45^{\circ} \mathrm{C}$ \\
\hline Specific Gravity & ASTM D-70 & $25^{\circ} \mathrm{C}$ & 1.031 \\
\hline Flash point & ASTM D-92 & Cleveland, ${ }^{\circ} \mathrm{C}$ & $320^{\circ} \mathrm{C}$ \\
\hline Viscosity by & & $135^{\circ} \mathrm{C}, \mathrm{CP}$ & $487.5^{\circ} \mathrm{C} \mathrm{p}$ \\
\hline $\begin{array}{l}\text { used Rotational } \\
\text { Viscosity }\end{array}$ & & $165^{\circ} \mathrm{C}, \mathrm{Cp}$. & $125^{\circ} \mathrm{C} p$ \\
\hline Fire point & ASTM D-92 & Cleveland, ${ }^{\circ} \mathrm{C}$ & $363^{\circ} \mathrm{C}$ \\
\hline
\end{tabular}

\subsection{Natural rock asphalt}

The NRA used in this work was collected from Al-Wafaa city in Al-Anbar province (ENRA). Table 2 shows some properties of ENRA, while Table 3 shows the elemental analysis of ENRA.

Table 2. Properties of ENRA

\begin{tabular}{|c|c|c|c|}
\hline Test & Method & Unit & Results \\
\hline Flash point & ASTM D-92 & ${ }^{\circ} \mathrm{C}$ & $\begin{array}{c}\text { Above } \\
350\end{array}$ \\
\hline $\begin{array}{c}\text { Penetration @ } 25^{\circ} \mathrm{C}, 10- \\
1 \mathrm{~mm}\end{array}$ & ASTM D5 & - & 0 \\
\hline Softening point @ 25ㅇ & ASTM D36 & ${ }^{\circ} \mathrm{C}$ & 192 \\
\hline Specific gravity @ $25^{\circ} \mathrm{C}$ & ASTM D3289 & - & 1.025 \\
\hline Ash content & ASTM D3174 & $\%$ & 22.39 \\
\hline Moisture content & ASTM D3173 & $\%$ & 2.13 \\
\hline Volatile matter & ASTM D3175 & $\%$ & 50.65 \\
\hline Fixed carbon & ASTM D3172 & $\%$ & 39.36 \\
\hline Solubility in CS2 & ASTM D4 & $\%$ & 60.42 \\
\hline Color in mass & Visual/sensory & - & Black \\
\hline Color in steak or powder & & - & Brown \\
\hline $\begin{array}{l}\text { Solubility in } \\
\text { trichloroethylene }\end{array}$ & ASTM D2042 & $\%$ & 67 \\
\hline Test & Method & Unit & Results \\
\hline
\end{tabular}

Table 3. Elemental properties of ENRA

\begin{tabular}{cccc}
\hline Test & Method & Unit & Results \\
\hline Carbon & ASTM D5291 & $\%$ & 74.60 \\
Hydrogen & & $\%$ & 7.15 \\
Nitrogen & & $\%$ & 0.69 \\
Oxygen & & $\%$ & 3.18 \\
Sulphur & Loco's Elemental analyzer & $\%$ & 5.27 \\
\hline
\end{tabular}

\subsection{Preparation of samples}

(1) Heating the sample at a temperature of up to $150^{\circ} \mathrm{C}$, then filling in small cans of size $1000 \mathrm{~g} / \mathrm{cm}^{3}$, primarily selected the suitable tests for asphalt such as (penetration, softening point, viscosity, ductility, density, flash \& fire point) before adding the additive ENRA.

(2) Recording the primary result of virgin asphalt before adding the ENRA, then heating the new sample and also filling in special tubes that are $500 \mathrm{~g} / \mathrm{cm}^{3}$.

(3) Adding the ENRA in different present 5\%, 10\%, 20\%, and $30 \%$ to each $100 \mathrm{~g}$ of virgin asphalt with a mixing speed of (1000-2000) rpm at a duration time between (10-20) min until the mixture becomes homogeneous $100 \%$ under a temperature of $100-150^{\circ} \mathrm{C}$.

\subsection{Asphalt testing}

\subsubsection{Penetration test of asphalt binder}

The Bitumen penetration test measures the stiffness and softness of asphalt binder by evaluating the depth in millimeters to which the standard loaded needle penetrates perpendicularly in 5 seconds, although preserving the temperature of the asphalt binder taster at $25^{\circ} \mathrm{C}$. Other consistency tests are used for tars, cutbacks, and emulsions [14].

\subsubsection{Softening point test}

The temperature at which asphalt binder or tar softens is known as the softening point. When heated below water or glycerin, it is the temperature in ${ }^{\circ} \mathrm{C}$ at which a standard ball permits through a sample of bitumen in a mold and descends to a height of $2.5 \mathrm{~cm}$. Before being utilized on the roadways, the asphalt binder must be suitably fluid [15]. 


\subsubsection{Flash and fire point}

Cleveland Open Cup Tester's Standard Experiment Method for Flash and Fire Points. The flash point of a material is the minimum temperature at which a test flame effects the substance's vapors to catch fire for a limited period of time. The fire point is the minimum temperature at which the material ignites and burns for at least five seconds when exposed to the test flame [16].

\subsubsection{Rotational viscometer}

It is used in high-temperature industrial and construction applications to test the viscosity of asphalt binders. This size is specified by the Super pave performance grade (PG) asphalt binder. The Rotational viscometer test may be evaluated at a variety of temperatures, but because production and construction temperatures are similar, the Super pave performance grade of bitumen test is always evaluated at $275^{\circ} \mathrm{F}\left(135^{\circ} \mathrm{C}\right)[17]$ and other test have been tested for bitumen such as ductility and specific gravity. Figure 1 shows the diagram of the asphalt tests.

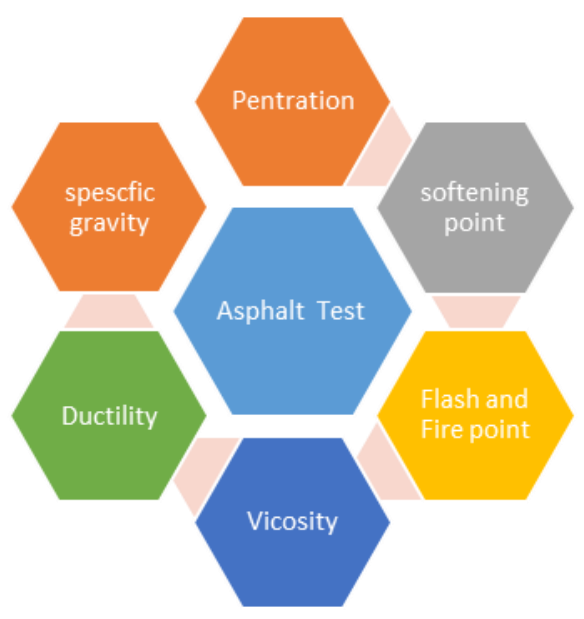

Figure 1. Diagram of the asphalt test

\section{RESULTS AND DISCUSSIONS}

In the study, the enhanced bitumen was produced by adding El Jebha rock asphalt from ENRA. The addition of ENRA to the virgin bitumen (40-50), which is produced by Al-anbar Refinery with different percentages $(5 \%, 10 \%, 20 \%$, and $30 \%$ by weight of bitumen) of ENRA to pure bitumen. The rheological properties were found by testing asphalt for penetration, ductility, softening point, kinematic viscosity, flash point and fire point. The Softening Point test of asphalt binder is prepared to determine the consistency of bitumen.

This test provides an idea of the temperature at which the bitumen attains an assured viscosity. The results of the softening point in Figure 2 show that the temperature at which the bitumen reaches a particular degree of softening has increased with the addition of ENRA. The Penetration test of bitumen is used to measure the consistency of bitumen.

Figure 3 shows the effect of ENRA on the degree of penetration, as the addition percentage decreases the permeability of bitumen (penetration). The ductility test is used to label the ductile and tensile performance of bitumen binders. The Effect of ENRA on the Ductility of Virgin Bitumen shows that increasing ENRA percentage decreases ductility. The other test is viscosity. It is used to measure resistance to the flow of liquid under the influence of gravity.

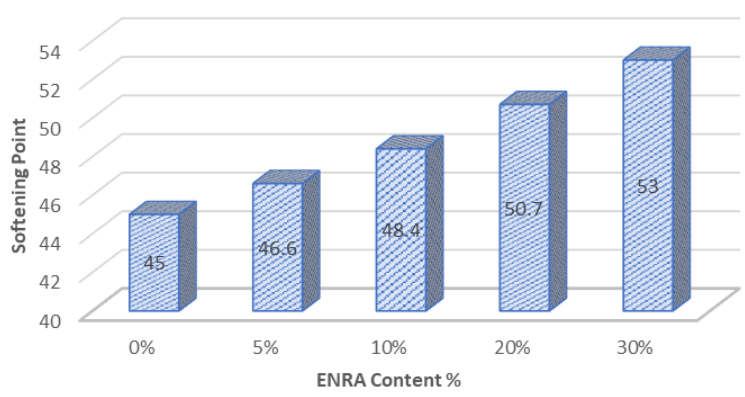

Figure 2. The effect of ENRA content on the softening Point of bitumen

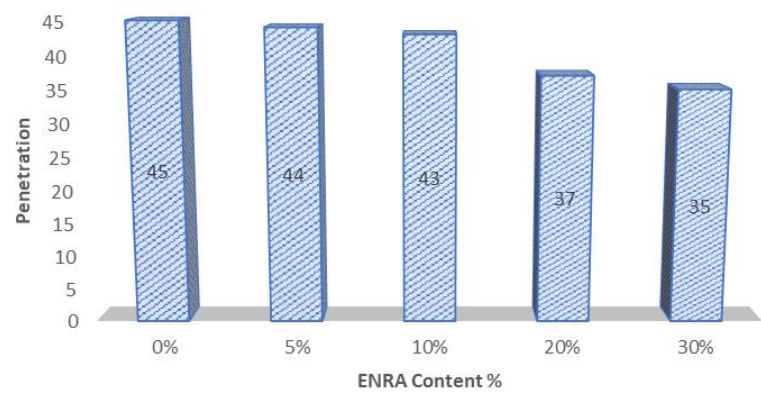

Figure 3. The effect of ENRA content on the penetration of bitumen

Figure 4 shows the results when increasing ENRA percentage due to an increase in viscosity at temperatures of $135 \mathrm{C}^{\circ}$ and $165 \mathrm{C}^{\mathrm{o}}$. The high value of viscosity means that the asphalt has high resistance to deformation at a given rate. The last test of bitumen is flash and fire point. It provides a degree of critical temperatures beyond which the asphalt binder should not be exposed to. Thus, these critical temperatures help in preventing a hazardous situation (5). The summary results for all the tests in this study are shown in Table 4.

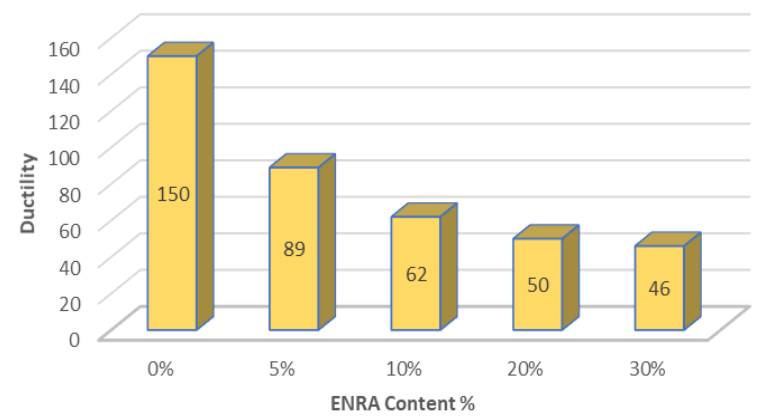

Figure 4. The effect of ENRA content on the ductility of bitumen

The results in Figure 5 indicate a decrease in the value of the specific gravity, which is considered as an indicator that the amount of mineral impurities is less, and this is an important indicator for extracting the impurities from the bitumen binder. The other test of bitumen is flash and fire point. It provides a degree of critical temperature beyond which the asphalt binder should not be exposed to. Thus, these critical temperatures help in preventing a hazardous situation. 
Table 4. Summary results for all the tests in this project

\begin{tabular}{ccccccccc}
\hline ENRA\% & Penetration & $\begin{array}{c}\text { Softening } \\
\text { Point }\end{array}$ & Ductility & $\begin{array}{c}\text { Specific } \\
\text { gravity }\end{array}$ & $\begin{array}{c}\text { Flash point } \\
\mathbf{C}^{\mathbf{0}}\end{array}$ & $\begin{array}{c}\text { Fire point } \\
\mathbf{C}^{\mathbf{o}}\end{array}$ & $\begin{array}{c}\text { viscosity at } \\
\mathbf{1 3 5 C}^{\mathbf{0}}\end{array}$ & $\begin{array}{c}\text { viscosity at } \\
\mathbf{1 6 5 C}^{\mathbf{0}}\end{array}$ \\
\hline $0 \%$ & 45 & 45 & 150 & 1.058 & 320 & 362 & 487.5 & 125 \\
$5 \%$ & 44 & 46.6 & 89 & 1.051 & 284 & 319 & 585 & 144 \\
$10 \%$ & 43 & 48.4 & 62 & 1.042 & 245 & 270 & 683 & 163.5 \\
$20 \%$ & 37 & 50.7 & 50 & 1.041 & 221 & 265 & 877.5 & 200 \\
$30 \%$ & 35 & 53 & 46 & 1.039 & 202 & 261 & 1071 & 237.5 \\
\hline
\end{tabular}

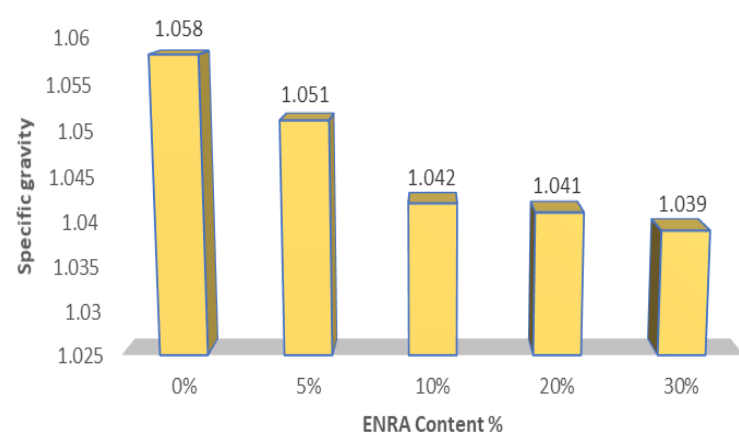

Figure 5. Effect of ENRA content on the specific gravity of bitumen

Figure 6 shows a decrease in the minimum temperature at which the drawing line causes vapors from the substance to ignite in the form of a flash under specific test conditions. But it remains within the safety limits.

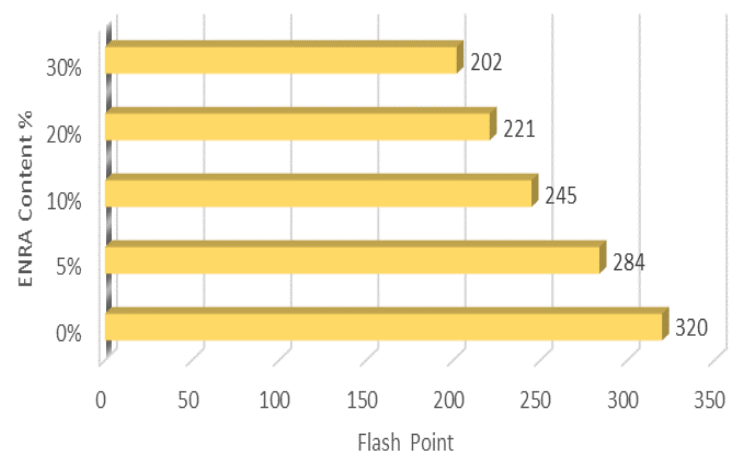

Figure 6. Effect of ENRA content on the flash point of bitumen

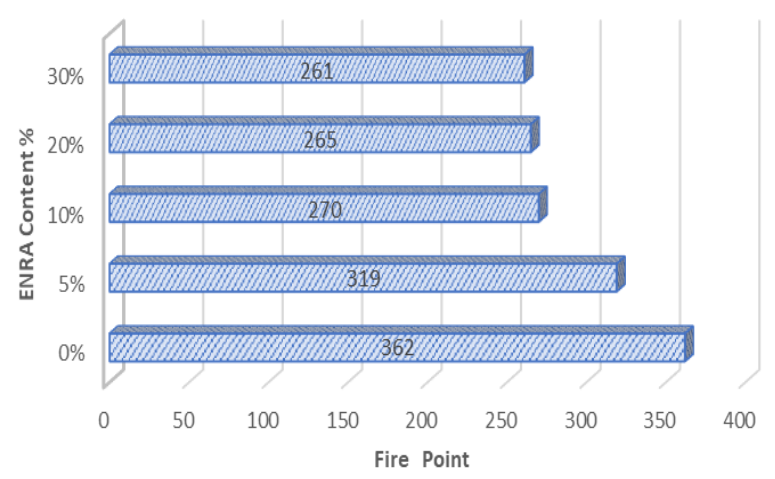

Figure 7. Effect of ENRA content on the fire point of bitumen

Figure 7 shows the lowest temperature at which the application of the test flame leads to ignition and burning of the material, which is a very important test in terms of safety, as the results indicate a decrease in the ignition point, but it remains within the safety limits.

The last test is viscosity. It is used to measure resistance to the flow of liquid under the influence of gravity. Figure 8 shows the results when increasing ENRA percentage due to an increase in viscosity at temperatures of $135 \mathrm{C}^{\circ}$ and $165 \mathrm{C}^{\circ}$. The high value of viscosity means that the asphalt has high resistance to deformation at a given rate.

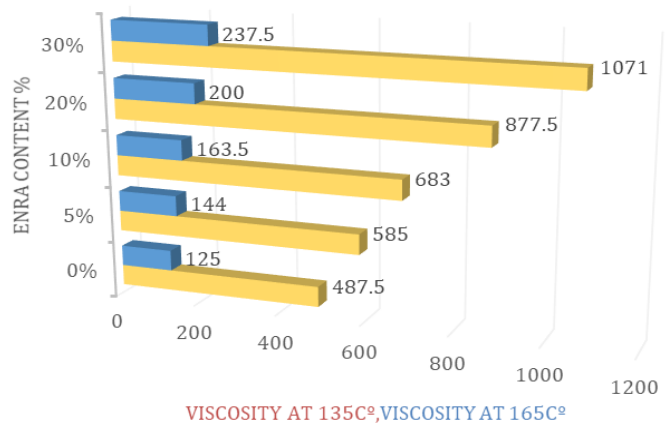

Figure 8. Effect of ENRA content on the viscosity at various temperature of bitumen

\section{CONCLUSION}

The mechanical characteristics of bitumen are greatly influenced by the rheological characteristics of the asphalt binder. As this study showed positive results in improving the properties of asphalt by increasing the age of the road, increasing resistance to deformations and preserving performance at high temperatures. This was observed through the investigation that showed the stiffening effect produced by the adding of natural asphalt into the binder occurs in the modified asphalt binders. Exactly, the posterior observations were made on the virgin binder and four modified binders add in various dosages of natural rock asphalt.

The adding of natural asphalt to virgin asphalt binder produced a drop in penetration and ductility, and a rise in the ring and ball softened the point. The modified asphalt by rock asphalt becomes stiffens. The anti-deformation aptitude and the high-temperature performance clearly advance where the high value of viscosity means that the asphalt has high resistance to deformation at a given rate. The adding of natural asphalt advances temperature durability and decreases temperature sensitivity.

The above results support this project hypothesis since the rheological properties of the asphalt have improved with NRA addition. where the resulting mixture becomes harder and has a softening point that happens at a higher temperature than the virgin asphalt. 


\section{ACKNOWLEDGMENT}

The authors would like to acknowledge the contribution of the University of Anbar (www.uoa.edi.iq) via their prestigious academic staff in supporting this research with all the required technical and academic support.

\section{REFERENCES}

[1] McIntosh, J. (2008). The Ancient Indus Valley: New Perspectives. Abc-Clio.

[2] Airey, G.D., Brown, S.F. (1998). Rheological performance of aged polymer modified Bitumens. Journal of the Association of Asphalt Paving Technologists, 67.

[3] Du, S.W., Liu, C.F. (2012). Performance evaluation of high modulus asphalt mixture with Button rock asphalt. Advanced Materials Research, 549: 558-562. https://doi.org/10.4028/www.scientific.net/AMR.549.55 8

[4] Syroezhko, A.M., Ralis, R.V. (2007). Manufacture of asphalts of different brands by compounding vacuum residue with natural asphaltite. Petroleum Chemistry, 47(4): 299-300.

[5] Lv, S., Wang, S., Guo, T., Xia, C., Li, J., Hou, G. (2018). Laboratory evaluation on performance of compoundmodified asphalt for rock asphalt/styrene-butadiene rubber (SBR) and rock asphalt/nano- $\mathrm{CaCO}_{3}$. Applied Sciences, $8(6)$ : 1009. https://doi.org/10.3390/app8061009

[6] Arisona, A., Nawawi, M., Nuraddeen, U.K., Hamzah, M. (2016). A preliminary mineralogical evaluation study of natural asphalt rock characterization, southeast Sulawesi, Indonesia. Arabian Journal of Geosciences, 9(4): 272. https://doi.org/10.1007/s12517-015-2288-3

[7] Zhang, C., Li, Y., Cheng, X., Liang, S., Guo, X., Zhao, H., Song, Y. (2018). Effects of plasma-treated rock asphalt on the mechanical properties and microstructure of oil-well cement. Construction and Building Materials, 186: $163-173$ https://doi.org/10.1016/j.conbuildmat.2018.07.133

[8] Zhong, K., Yang, X., Luo, S. (2017). Performance evaluation of petroleum bitumen binders and mixtures modified by natural rock asphalt from Xinjiang China. Construction and Building Materials, 154: 623-631. https://doi.org/10.1016/j.conbuildmat.2017.07.182

[9] Erkuş, Y., Baha, K.Ö.K., Yilmaz, M. (2020). The effects of Iraq natural asphalt on mechanical properties of bituminous hot mixtures. Teknik Dergi, 33(2).
[10] Ma, F., Zhang, C. (2013). Road performance of asphalt binder modified with natural rock asphalt. In Advanced Materials Research, 634-638(1): 2729-2732. https://doi.org/10.4028/www.scientific.net/AMR.634638.2729

[11] Liu, C., Lv, S., Jin, D., Qu, F. (2021). Laboratory investigation for the road performance of asphalt mixtures modified by rock asphalt-styrene butadiene rubber. Journal of Materials in Civil Engineering, 33(3): 04020504. https://doi.org/10.1061/(ASCE)MT.19435533.0003611

[12] Li, L., He, Z., Liu, W., Hu, C. (2019). A study on the application of rock asphalt from Sichuan China based on anti-rutting performance. Applied Sciences, 9(5): 870. https://doi.org/10.3390/app9050870

[13] Yilmaz, M., Çeloğlu, M.E. (2013). Effects of SBS and different natural asphalts on the properties of bituminous binders and mixtures. Construction and Building Materials, 44: 533-540. https://doi.org/10.1016/j.conbuildmat.2013.03.036

[14] American Society of Testing and Materials. (1997). Standard Test Method for Penetration of Bituminous Materials. Annual Book of ASTM Standards, Section 4, Volume 04.03. http://www.shxf17.com/pdf/ASTMD52006.pdf.

[15] Standard Test Method for Softening Point of Bitumen (Ring and Ball Apparatus). American Society of Testing and Materials, 1995.Annual Book of ASTM Standards, Section 4, Volume http://www.shxf17.com/pdf/ASTMD36-95.pdf.

[16] Standard Test Method for Flash Point by Cleveland Open Cup. American Society of Testing and Materials, D921996. Annual Book of ASTM Standards, Section 4, Volume $\quad 04.03$. https://www.stanhopeseta.co.uk/product/pm-93-pensky-martens-flash-pointtester/?gclid=CjwKCAiAm7OMBhAQEiwArvGi3MIii W_5x4mwLy3YmdeJO4RbeyFQ4bGkQyIDbdIpjSeBÑey310_BoCEHUQAvD_BwE.

[17] Chebykin, D., Heller, H.P., Dubberstein, T., Korobeinikov, I., Volkova, O. (2017). Viscosity measurement of slags using rotating bob and vibrating finger viscometer. ISIJ International, 57(8): 1319-1326.

\section{NOMENCLATURE}

$\begin{array}{ll}\text { NRA } & \text { Natural Rock Asphalt } \\ \text { RA } & \text { Rock Asphalt } \\ \text { BRA } & \text { Buton rock asphalt } \\ \text { SBS } & \text { Styrene butadiene styrene } \\ \text { ENRA } & \text { El Jebha Natural rock asphalt }\end{array}$

